\title{
Bilateral acute parotitis following insertion of a Sengstaken-Blakemore tube
}

A 56-year-old man with hepatitis B-related cirrhosis was admitted with massive hematemesis. Three months previously he had undergone upper endoscopy at another hospital and was diagnosed as having esophageal varices. However, no endoscopic therapy was carried out. On physical examination, the patient's blood pressure was $76 / 40 \mathrm{~mm} \mathrm{Hg}$, his pulse rate was $136 \mathrm{bpm}$, and his respiratory rate was 26/min. Despite aggressive therapy with fluids and blood components the patient could not be stabilized, and a Sengstaken-Blakemore tube was inserted. Eleven hours after the insertion of the tube, the patient developed swelling over both his parotid glands ( Fig. 1), with local rise in temperature and tenderness.

Neck ultrasonography revealed bilateral generalized swelling of the parotid glands, without duct dilation. An otolaryngologist was consulted and bilateral acute parotitis was diagnosed. The patient was started on antibiotic therapy with ceftriaxone, the gastric and esophageal balloons were immediately deflated, and the Sengstaken-Blakemore tube was removed. There was no re-bleeding in the next 48 hours, and the patient was given terlipressin. The parotitis resolved completely after 72 hours of removal of the Sengstaken-Blakemore tube. While upper endoscopy was being considered, on the fifth day in hospital the patient again had massive hematemesis and died.

Transient parotitis following the use of lidocaine spray [1] and midazolam [2] for upper endoscopy has been reported previously. In addition, upper endoscopy may also cause parotitis $[3,4]$. Although the exact mechanism is unknown, venous congestion leading to straining, and parasympathetic stimulation during the procedure causing parotid vasodilation and

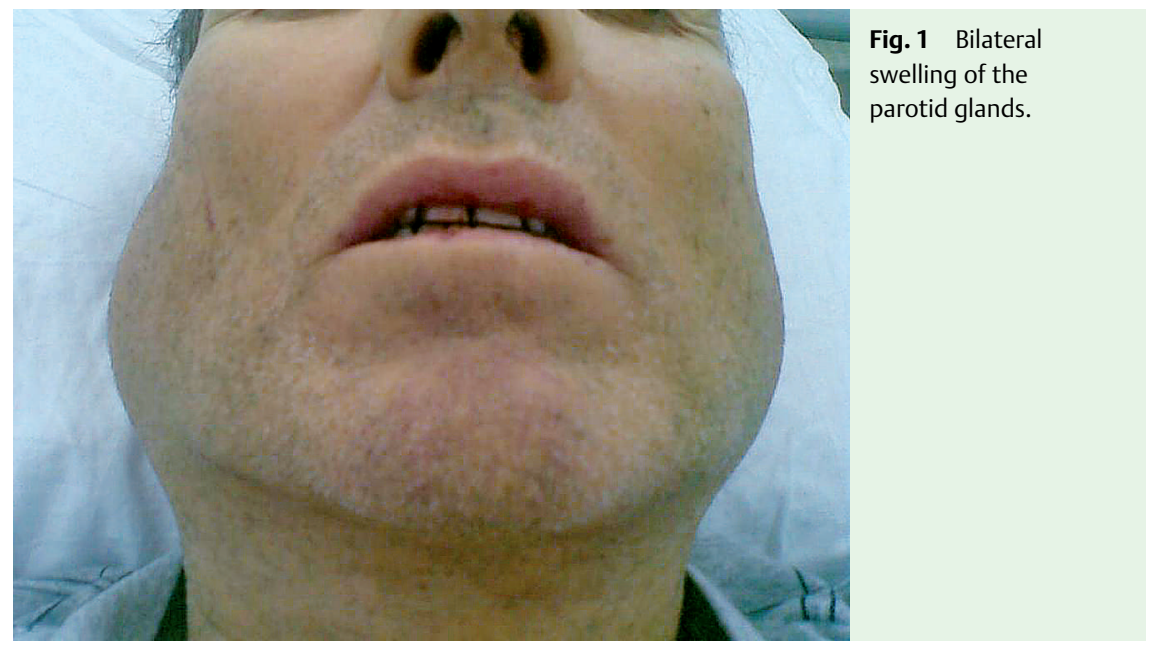

transient enlargement, have been suggested as possible mechanisms [3]. Furthermore, recently, parotitis associated with double-balloon endoscopy has been reported in two cases [5,6]. However, to our knowledge, parotitis associated with insertion of a Sengstaken-Blakemore tube has not been reported before. $\mathrm{Al}$ though the reason for its occurrence is unclear, clinicians should be aware of this rare complication.

\section{Endoscopy_UCTN_Code_CPL_1AH_2AC}

\section{F. Tekin, O. Ozutemiz, S. Bicak, N. Oruc,}

\section{T. Ilter}

Department of Gastroenterology, Ege University Medical School, Izmir, Turkey

\section{References}

1 Sagar J, Chavan VA, Shah DK. Acute parotiditis and facial nerve palsy - unusual side effects of Xylocaine spray. Endoscopy 2007; 39 Suppl 1: E189

2 Gültuna S, Usküdar O, Yüksel I et al. Transient parotitis after conscious sedation for endoscopy. Endoscopy 2009; 41 Suppl 2: E53
3 Nijhawan S, Rai RR. Parotid swelling after upper gastrointestinal endoscopy. Gastrointest Endosc 1992; 38: 94

4 Shields HM, Soloway RD, Long WB et al. Bilateral recurrent parotid gland swelling after endoscopy. Gastroenterology 1977; 73: $164-165$

5 Yen HH, Su WW, Chiu YH et al. Acute parotitis after double-balloon endoscopy. Gastrointest Endosc 2008; 68: 1017 -1019

6 Kekilli M, Onal IK, Kurt M et al. Parotitis during oral double-balloon enteroscopy: an unexpected but benign finding. Am J Gastroenterol 2009; 104: 533-534

\section{Bibliography}

DOI 10.1055/s-0029-1214854

Endoscopy 2009; 41: E206

(c) Georg Thieme Verlag KG Stuttgart · New York . ISSN 0013-726X

\section{Corresponding author}

\section{Dr. F. Tekin}

Ege Universitesi Tip Fakultesi

Gastroenteroloji Bilim Dali

Bornova 35100

Izmir

Turkey

Fax: +90-232-3427764

drtekinfatih@yahoo.com 